\title{
Editorial - Message from the President
}

Pavel Exner, President of the EMS

Dear EMS members, dear friends,

Another calendar page turns, and another year heads for the history books. We may have to wait a decade for the next prime numbered year, but many mathematical and mathematics-related events will occur much sooner. To begin with, the year we are entering has been declared The Year of Mathematical Biology, and I think this is a good omen. We are all now convinced that mathematics is omnipresent, but this truth has dawned in different ways in different fields. It took over two centuries from its first successful marriage with physics, before mathematics started to be applied seriously to biological and social systems. The explosive growth, over the last six or seven decades, of our knowledge of biological mechanisms provides strong motivation to focus on questions which mathematicians and biologists could address together.

There will be many events over the year, such as the European Conference on Mathematical and Theoretical Biology in Lisbon (the programme of which includes the annual lecture jointly organized by the EMS and the Bernoulli Society), the EMS Joint Mathematical Weekend in Joensuu, summer schools, and a great deal more.

The year 2018 will be also important in the life of our society. As happens every second year, the EMS Council (our highest authority) will meet to discuss both our achievements and our next goals. The June Council Meeting in Prague will need to elect the new EMS president, to make decisions about the society's budget, and to settle other important questions related to the EMS's mission and smooth running.

It is satisfying to note that the number of EMS members, both individual and corporate, continues to grow steadily on average. The conditions in which we live are not all the same, of course, and it is encouraging indeed when the national society of a country plagued by serious political and economic problems once again fulfils its membership duties. (They could serve as an example to other corporate members whose approach is more - shall we say - relaxed.) The EMS is not a rich society even compared to some of our members, to say nothing of our partners overseas, but we are doing well financially and are delighted to be able to support more summer schools, conferences, distinguished speakers, and other activities than ever before.

As usual, the turn of the year brings a renewal of our standing committees, the backbone of the society's work. In some, changes are minimal, in others substantial (in part due to the eight-year cap on committee service). This year, the Applied Mathematics and Ethics Committees will undergo the biggest changes, with at least a half of their membership renewed. Let me take this opportunity to thank all departing committee members for their

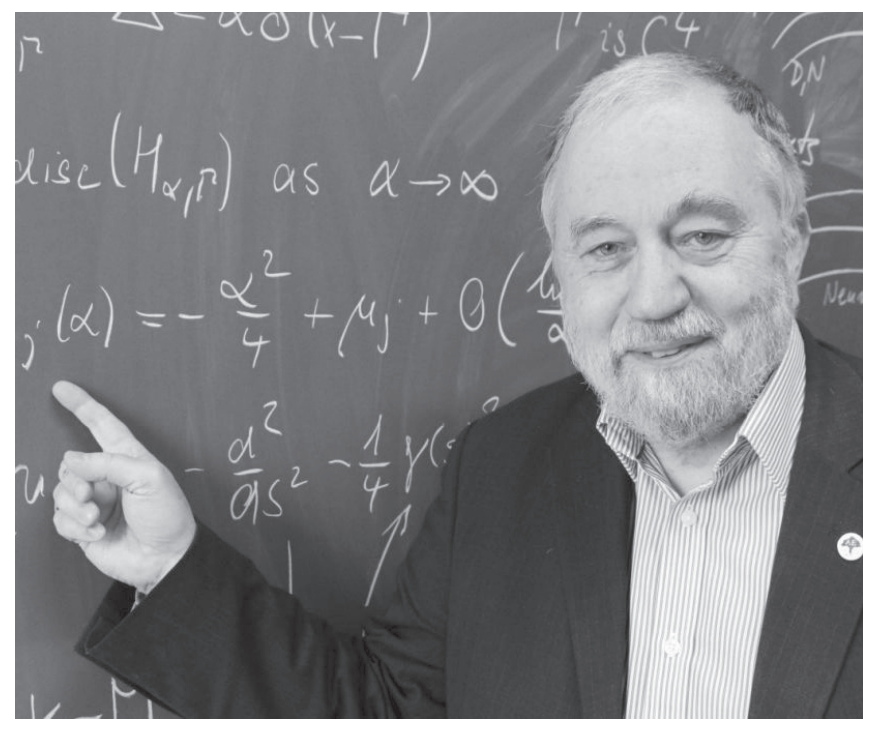

hard work, and to wish all newcomers success and satisfaction in working towards common goals.

Our gratitude is owed also to all those who work for the broader European mathematical community, in a wide variety of roles including for EU-MATHS-IN, EuDML, on the boards of mathematical journals and research centres, prize committees, and in a multitude of other ways.

The coming year also heralds exciting mathematical events worldwide, principally the International Congress in Mathematicians at the beginning of August in Rio de Janeiro, to which we are looking forward. By that time, we will also know the location of the 2022 ICM. As representatives of all mathematicians on our continent, we express no preference on the competition between Paris and Saint Petersburg, but we have no doubt that either choice will lead to a wonderful meeting. We are glad that, either way, after sixteen years the congress will return to the continent of its birth.

We may be European patriots, but at the same time we do not forget that there is a single world of mathematics, and we continue working to make connections all over the globe. The EMS has recently completed our list of cooperation agreements with major mathematical societies on other continents, by signing an agreement with the Chinese Mathematical Society. We hope it will lead to exciting joint ventures.

The Chinese note brings to mind yin and yang, and with cooperation naturally comes competition. To give one example, let me mention zbMATH. We are pleased that FIZ Karlsruhe, our partner in this enterprise, has had its financial support renewed, guaranteeing that the healthy competition with MathSciNet, beneficial for the whole mathematical community, will continue. We have just signed a new agreement fixing the EMS's involvement in the future development of zbMATH, and we are 
ready to work on further improvements of this great reference tool.

A year ago, I mentioned here the worrying state of the world, and I have to say that the situation has not improved - rather the opposite, with no need to list all the neuralgic points of the globe. We can do little to influence those political tectonic processes, but it is important to preserve and strengthen the esprit de corps, and to oppose the regular calls to ostracize some or other part of our community. A good example of such an attitude was the Second Caucasian Conference which convened (after a one-year delay) in the east of Turkey. I thank those who attended despite pressure they faced at home, and I hope this tradition will continue.

Having said that, I wish all of you good health and a lot of interesting mathematics in 2018. 